\title{
PERANCANGAN FILM DOKUMENTER KEBUDAYAAN SUKU SASAK DESA BAYAN
}

\author{
Yudha Delonix Renzina \\ Institut Seni Indonesia Yogyakarta \\ yudhadelonix@yahoo.com
}

\begin{tabular}{|c|c|}
\hline ARTICLE INFO & ABSTRACT \\
\hline $\begin{array}{l}\text { Article history: } \\
\text { Received: } 15 \text { Desember } 2018 \\
\text { Revised: } 28 \text { Februari } 2019 \\
\text { Accepted: } 15 \text { Maret } 2019\end{array}$ & $\begin{array}{l}\text { Television shows are currently dominated by programs such as } \\
\text { reality shows, infotainment, etc. This situation inspiring Kompas TV } \\
\text { to give different shows. Information and education are the main } \\
\text { things that want to be presented to viewers. Through the "Explore }\end{array}$ \\
\hline $\begin{array}{l}\text { Keywords: } \\
\text { Culture } \\
\text { Documenter } \\
\text { Sasak Tribe }\end{array}$ & $\begin{array}{l}\text { Indonesia-Sasak Tribe" program, viewers are invited to know more } \\
\text { closely and clearly about the cultures in various parts of Indonesia. } \\
\text { "Explore Indonesia" is a documentary genre show. Documentary } \\
\text { video is the most appropriate media to display a cultural reality and } \\
\text { visual and audio. The Sasak tribe is one of the interesting cultures in } \\
\text { Indonesia. Traditional houses, arts, and the daily lives of the unique } \\
\text { Sasak people make this tribe a tourist attraction on the island of } \\
\text { Lombok. }\end{array}$ \\
\hline
\end{tabular}

\section{PENDAHULUAN}

Kebudayaan merupakan suatu cerminan karakter atau ciri khas dari suatu bangsa, karena kebudayaaan merupakan warisan langsung dari leluhur atau nenek moyang bangsa tersebut. Pada abad ke-19, ahli antropologi Inggris Edward B. Taylor (1817) mendefinisikan budaya dalam bukunya yang berjudul Primitive Culture, sebagai "suatu kebulatan yang kompleks dan mencakup pengetahuan, kepercayaan, seni, moral, hukum, adat, dan kemampuan atau kebiasaan lainnya yang diperoleh manusia sebagai anggota masyarakat (Danesi, 2010:43). Bangsa Indonesia merupakan bangsa yang kaya akan budaya, lebih dari 20 suku terdapat di Indonesia dan lebih dari 100 budaya ada di Indonesia. Mempelajari adat istiadat sebuah suku bangsa berarti mempelajari pula entitas kebudayaan bangsa. Bukan hanya itu, dengan mempelajarinya berarti telah ikut melestarikannya. Hal ini yang seharusnya penting untuk dilakukan, sebab aneka ragam suku bangsa Indonesia adalah kekayaan bangsa yang tak ternilai dan tak ada duanya.

Salah satu dari sekian banyak suku yang terdapat di Indonesia adalah suku Sasak. Suku Sasak adalah suku terbesar di propinsi yang berada di antara Bali dan Nusa Tenggara Timur. 
Suku Sasak masih dekat dengan suku bangsa Bali, tetapi suku ini sebagian besar memeluk agama Islam (Febriana, 2007:8). Lombok yang masuk dalam Wonderful Indonesia merupakan salah satu tujuan perjalanan wisata para wisatawan baik lokal maupun mancanegara karena keindahan alamnya dan kebudayaan yang menarik. Salah satu tujuan para wisatawan ke pulau Lombok adalah untuk melihat suku Sasak secara langsung. Suku Sasak berada di kawasan Desa Bayan. Desa Bayan memiliki tempat yang berada di tengah pulau Lombok bagian utara, tepatnya di kaki gunung Rinjani. Masih belum banyak orang mengetahui tempat tersebut jika dibandingkan dengan Desa Sade yang berada di Lombok Barat, karena Desa Sade biasanya menjadi tempat tujuan wisatawan untuk membeli cinderamata khas Suku Sasak. Ada suatu keunikan yang dimiliki oleh Desa Bayan yang membuatnya sedikit berbeda dari Desa Sade yaitu penduduknya yang masih sangat tradisional dan masih sangat kental dengan adat istiadat dari Suku Sasak. Bahkan dari tempat tersebut dulunya dikenal dengan "Wetu Telu” (waktu tiga) dalam melaksanakan ibadah Sholat. Namun akses tempat ini yang sedikit sulit dikarenakan jarak dan transportasi yang minim membuat wisatawan tidak banyak yang mengetahui keberadaan Desa Bayan tersebut.

Untuk memperkenalkan budaya dari masyarakat suku Sasak Lombok ke masyarakat luas maka diperlukanlah suatu media yang tepat untuk mempromosikannya. Salah satu media yang dapat menjadi sarana promosi adalah film terutama film dokumenter. Film dokumenter menyajikan realita melalui berbagai cara dan dibuat untuk berbagai macam tujuan. Intinya, film dokumenter tetap berpijak pada hal-hal senyata mungkin (Effendy, 2002:12). Film dokumenter dapat menjadi media alternatif untuk mengakses informasi. Sekalipun berita juga merupakan salah satu sumber informasi. Tetapi informasi dalam berita hanya disajikan karena keaktualannya saja, sementara ada informasi yang justru nilai aktualitasnya tidak begitu penting tetapi unsur kedalamannyalah yang penting. Hal inilah yang menjadi salah satu kelebihan film dokumenter dibandingkan dengan berita.

Berdasarkan hal tersebut, maka media yang akan dipilih adalah film dokumenter karena media visual adalah media yang sangat cocok untuk memperlihatkan keanekaragaman budaya yang tampak. Diharapkan dengan adanya film dokumenter ini dapat membuka wacana masyarakat mengenai realita kebudayaan suku Sasak yang ada di pulalu Lombok. Memperkenalkan keragaman budaya Indonesia di mata kita. Selain itu nantinya juga diharapkan dapat menarik wisatawan baik lokal maupun mancanegara untuk berkunjung dalam rangka mendukung promosi program Visit Indonesia. 
Film adalah hasil dari perekaman sebuah visual bergerak ke dalam sebuah alat perekam. Apabila kita mencoba memahami dari arti dokumenter, kita dihadapkan pada dua hal yaitu pada sesuatu yang nyata atau faktual (ada atau yang terjadi) dan esensial, bernilai atau memiliki makna. Dalam dokumenter terkandung unsur faktual dan nilai. Intinya, meskipun banyak catatan lapangan, foto atau materi lain yang berisi rekaman peristiwa dan kejadian yang nyata, namun tidak semua hal itu memiliki nilai dokumenter. Hanya suatu materi yang sungguh bermakna bagi suatu lingkungan yang boleh disebut bernilai dokumenter (Wibowo, 1997:145).

Dalam buku Fajar Nugroho yang berjudul "Cara Pinter Bikin Film Dokumenter”, film secara umum dibagi menjadi dua unsur yaitu, unsur naratif dan unsur sinematik, dua unsur tersebut saling berhubungan untuk membentuk sebuah film. Jika hanya salah satu unsur saja yang terbentuk maka tidak akan menghasilkan sebuah film. Unsur naratif adalah bahan (materi) yang akan di olah, sedangkan unsur sinematik adalah cara (gaya) untuk mengolahnya, dalam film cerita, unsur naratif adalah perlakuan terhadap cerita film. Sementara unsur sinematik merupakan aspek-aspek teknis pebentuk sebuah film, unsur sinematik dibagi menjadi empat elemen pokok yakni, mise en scene, sinematografi, editing, dan suara.

a. Mise en scene adalah segala aspek yang berada di depan kamera yang akan direkam gambarnya.

b. Sinematografi secara umum dapat dibagi menjadi tiga aspek, yaitu kamera dan film, framing serta durasi gambar.

c. Editing merupakan tahap pasca produksi. Tahap ini berfokus untuk pemilihan serta penyambungan shot-shot yang telah diambil. Sehingga teknik yang digunakan untuk mengabungkan tiap shotnya cukup penting. Proses ini menggunakan software atau aplikasi tertentu sehingga hasil akhirnya tampak baik.

d. Suara dalam film adalah seluruh suara yang keluar dari gambar, yaitu dialog, musik, dan efek suara.

Ada beberapa pengertian budaya menurut beberapa ahli salah satunya adalah tokoh terkenal Indonesia yaitu Koentjaraningrat. Dalam bukunya pengantar Ilmu antropologi (1989:186), Koentjaraningrat mengemukakan bahwa yang dimaksud dengan kebudayaan merupakan wujud ideal yang bersifat abstrak dan tak dapat diraba yang ada di dalam pikiran manusia yang dapat berupa gagasan, ide, norma, keyakinan dan lain sebagainya. Dalam setiap kebudayaan terdapat unsur-unsur yang juga dimiliki oleh berbagai kebudayaan lain. 
Koentjaraningrat menyebutnya sebagai unsur-unsur kebudayaan yang universal yang meliputi: sistem religi dan upacara keagamaan, sistem dan organisasi kemasyarakatan, sistem pengetahuan, bahasa, kesenian, sistem mata pencaharian hidup, dan sistem teknlogi dan peralatan. Tiap-tiap unsur kebudayaan universal tersebut menjelma kedalam tiga wujud kebudayaan, yaitu (1) Wujud kebudayaan sebagai benda-benda hasil karya manusia, (2) Wujud kebudayaan sebagai sebuah kompleks dari ide-ide, gagasan, nilai-nilai, norma-norma, peraturan dan sebagainya dan (3) Wujud kebudayaan sebagai kompleks aktivitas serta tindakan berpola dan manusia di dalam suatu masyarakat.

\section{METODE PERANCANGAN}

Metode riset yang digunakan di sini adalah dengan menggunakan pendekatan etnografi. Etnografi merupakan salah satu jenis penelitian kualitatif yang banyak berkaitan dengan antropologi dengan tujuan mengetahui budaya suatu kelompok. Fokus penelitian dalam metode ini memandang pada peran dan fungsi kebudayaan pada individu dan sosial yang berkaitan dengan tradisi, perilaku, pola masyarakat serta suatu upaya-upaya kultural (Saebani, 2012:87). Tahapan proses perancangan ini adalah :

1. Tahap penentuan masalah

Setelah melihat fenomena yang telah didapat langkah berikutnya adalah melakukan penentuan masalah dengan cara melakukan observasi dan pencarian informasi dari beberapa sumber media, kemudian dilakukan analisa untuk ditarik menjadi sebuah identifikasi masalah.

2. Riset

Mencari data dari konsumen baik mengenai persepsi, respon, mereka terhadap video dokumenter dengan cara wawancara dan membagikan kuesioner. Setelah riset didapatkan, selanjutnya mencari tentang data-data yang berhubungan dengan fenomena yang telah ditentukan dan mencari literatur tentang teknik yang akan dilakukan untuk proses perancangan film.

\section{Konsep Desain}

Untuk menentukan konsep desain ini dilakukan dengan cara mengkaji sebuah film yang pernah dibuat dan melakukan kuisioner untuk menemukan karakteristik konsumen/target audiens. Kemudian dari sesuatu yang didapat sebelumnya antara fenomena, permasalahan dan hasil riset berupa karakteristik penonton, akan diolah sehingga menemukan keyword dari sebuah konsep.

4. Pra Produksi 
Proses ini merupakan proses mempersiapkan peralatan apa saja yang akan dibawa dan merancang budgeting atau dana yang akan dikeluarkan selama proses akan berlangsung.

\section{Produksi}

Tahap ini merupakan aktifitas inti dari membuat film. Para kru yang telah ada akan terjun langsung ke lokasi untuk membaur dengan warga sehingga tercipta atmosfir keterbukaan antara warga dengan kru. Selain itu perkenalan dan perizinan untuk mengambil gambar ada pada tahap ini. Kemudian pada tahap ini juga dilakukan pencatatan dan pengelompokkan seluruh kegiatan pengambilan gambar yang telah dilakukan. Sehingga akan memudahkan editor pada saat melakukan editing.

6. Pasca Produksi.

Proses pasca produksi merupakan pemindahan data dari alat rekam ke dalam komputer untuk selanjutnya melakukan proses editing. Tahap ini termasuk dengan pembuatan desain opening, super grafis, dan desain media pendukung.

\section{PEMBAHASAN}

\section{a. Studi Referensi}

1. "Eagle Award"

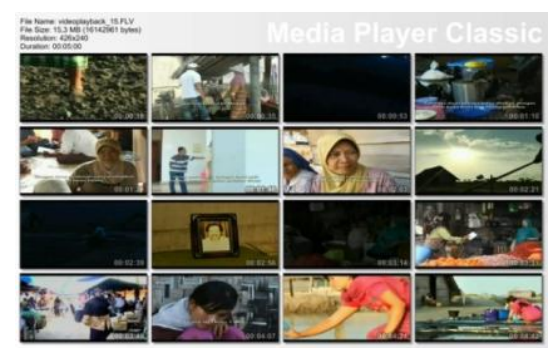

Gambar. 1 Video Garamku tak asin lagi

(Sumber:www.youtube.com)

Film buatan dua sineas muda asal Aceh ini menceritakan tentang perjuangan sekelompok wanita yang masih berjuang dalam melakukan tradisi lamanya untuk bertahan hidup, yaitu menjadi petani garam. Di tengah gencarnya produk impor yang memasuki tanah air, mereka tetap berjuang untuk mempertahankan apa yang telah lama menjadi sumber mata pencaharian mereka.

2. "Explore Indonesia" 


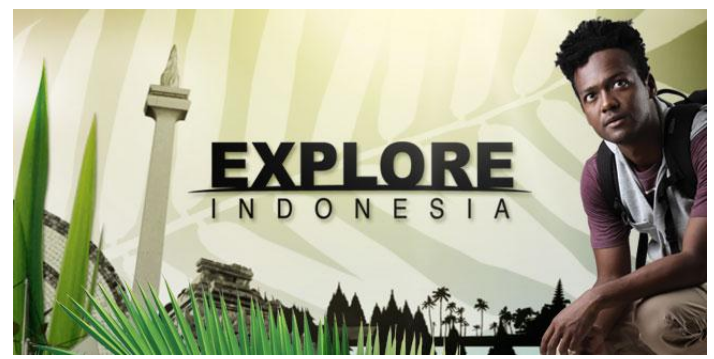

Gambar. 2 Opening Explore Indonesia di Kompas TV (Sumber: www.kompas.tv)

Explore Indonesia adalah salah satu program acara yang terdapat di Kompas TV, sebagai stakeholder. Dipandu oleh Kamga, program ini akan mengajak pemirsa mengeksplorasi lebih dalam tentang keindahan budaya dan sejarah Indonesia. Menemukan sesuatu yang baru di tempat lama, membangkitkan hal lama yang hampir punah serta menemukan tempat-tempat baru. Sebuah program dokumenter wisata yang mengekplorasi Indonesia dan menyajikannya dengan sisi-sisi berbeda.

\section{b. Konsep}

Konsep didapatkan dengan mencari sebuah keyword terlebih dahulu. Proses pencarian keyword dilakukan dengan menemukan beberapa kata kunci dari berbagai aspek yang telah diriset sebelumnya. Aspek itu meliputi fenomena, subjek, objek output, USP, kompetitor komparator, dan target segmen. Penulis telah melakukan survey sebelumnya sehingga menhasilkan data sebagai berikut:

\section{Demografi target segmen}

- Unisex (perempuan dan laki-laki).

- Tinggal di daerah perkotaan.

- Usia 25-35 tahun.

- SES menengah atas.

- Pendidikan setara sarjana.

- Menyukai ilmu pengetahuan sejarah dan juga kebudayaan.

- Menyukai tayanga televisi yang berbau edukasi, informatif, dan aktual.

\section{Psikografis target segmen}

Tertarik mengenai hal yang baru, senang bepergian, suka dengan kebudayaan Indonesia, sering menonton televisi, suka berinteraksi dengan orang lain, dan suka dengan keindahan alam.

\section{Karakteristik}

- Sudah mulai memasuki tingkat kematangan dalam hal berpikir. 
- Mulai/sudah berkeluarga, tertarik dengan tempat-tempat baru yang belum pernah disinggahi.

- Tidak terlalu tertarik lagi dengan program televisi yang berbau hiburan anak muda.

- Menyukai dengan hal yang baru.

- Selalu mengikuti perkembangan terhadap informasi.

Keyword yang akhirnya didapatkan disini adalah "Representation of Uniquely Culture". Keyword ini memiliki arti pemaparan atau gambaran dari sebuah kebudayaan yang sedang berkembang. Suku Sasak adalah suku yang unik dengan beragam kebudayaan dan kesenian yang ada. Mereka hidup di tengah masyarakat modern, namun tetap mempertahankan kebudayaan adatnya. Namun beberapa hal ada yang telah berubah di dalam adat mereka untuk menyesuaikan diri dengan kemajuan jaman. 


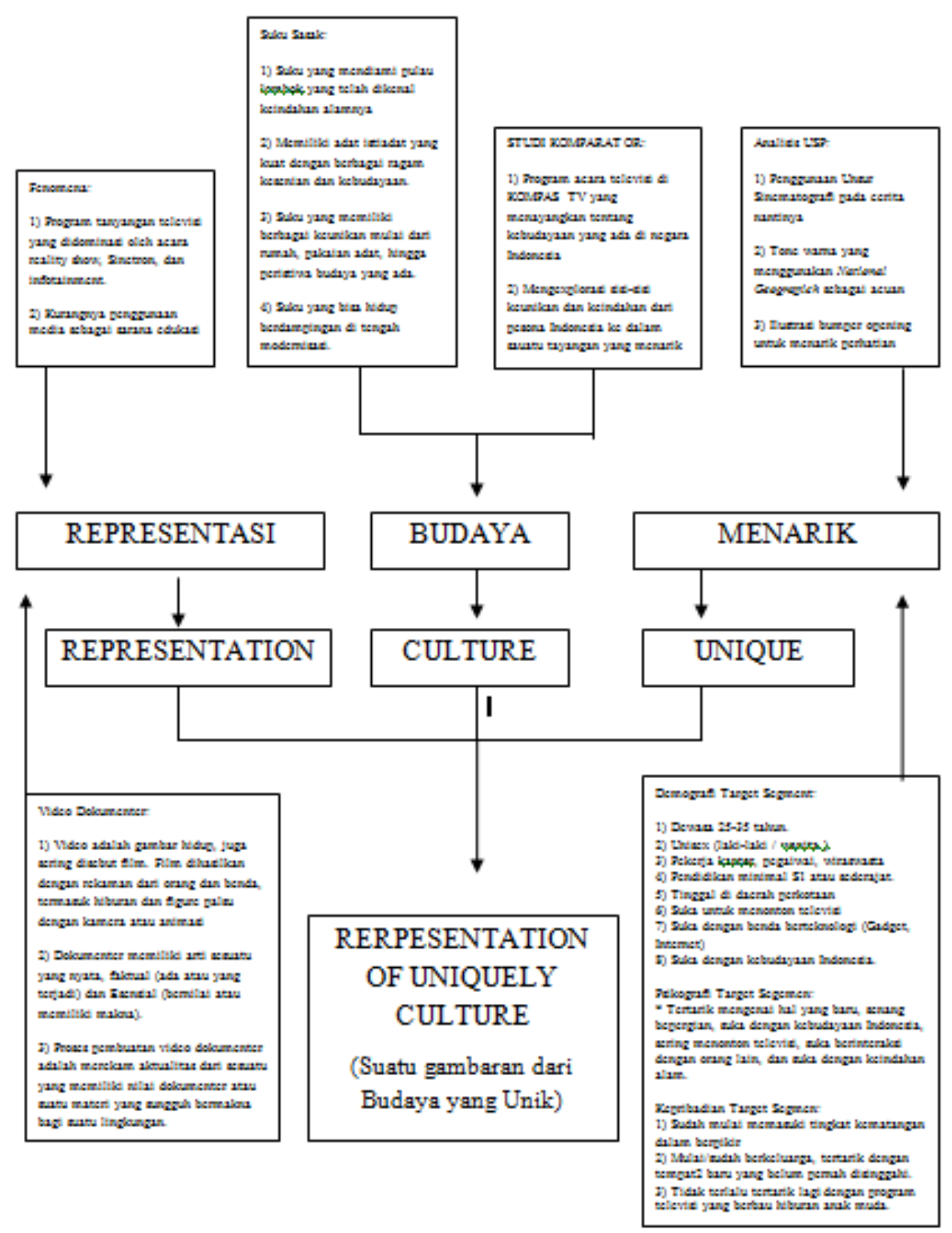

Gambar. 3 Unsur seni bangun Islam

(Sumber: Dokumentasi penulis)

\section{c. Karya Film Dokumenter}

Media utama dari perancangan ini adalah film dokumenter berdurasi 24 menit. Film dikemas dengan durasi yang tidak terlalu lama untuk menghindari kebosanan yang dapat muncul pada audience. Film berfokus pada keseharian, adat, dan kesenian yang dimiliki oleh Suku Sasak Bayan dengan menampilkan beberapa peristiwa adatnya secara langsung. 


\section{Susunan Isi Materi}

\section{a. Sekilas Pulau Lombok}

Berisi mengenai sekilas keindahan dari pulau Lombok, diseratai video pemandangan pantainya yang indah. Selain itu berisi mengenai penduduk pulau Lombok dan sekilas data penduduk Suku Sasak.

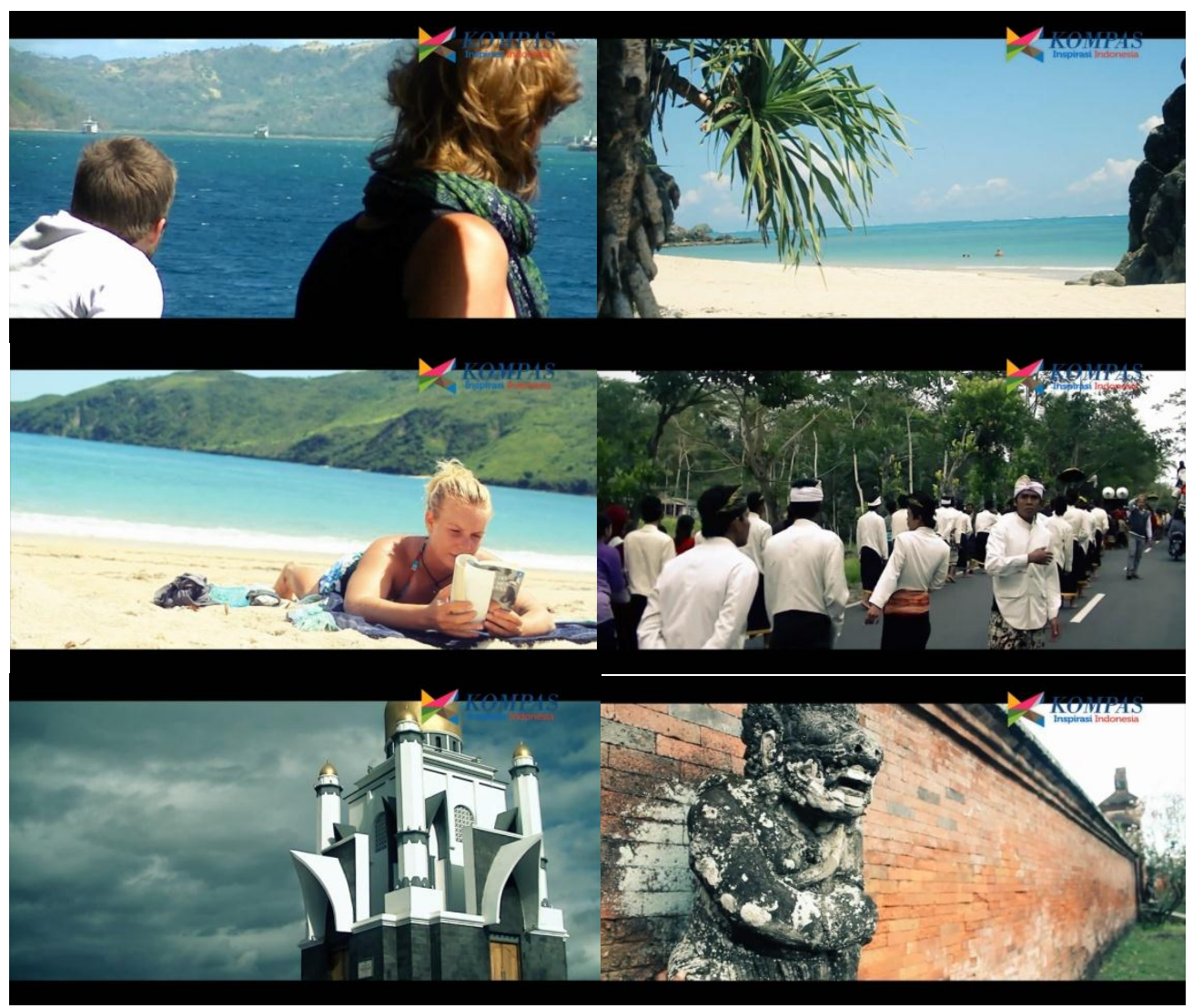

Gambar. 4 Sekilas Lombok dan Suku Sasak (Sumber: Dokumentasi penulis)

\section{b. Sekilas Suku Sasak}

Bagian selanjutnya adalah pembahasan mengenai siapa sebenarnya Suku Sasak ini. Terdapat Suku Sasak yang sudah modern dan ada pula Suku Sasak tradisional yang hidup dengan mempertahankan tradisi adatnya. 


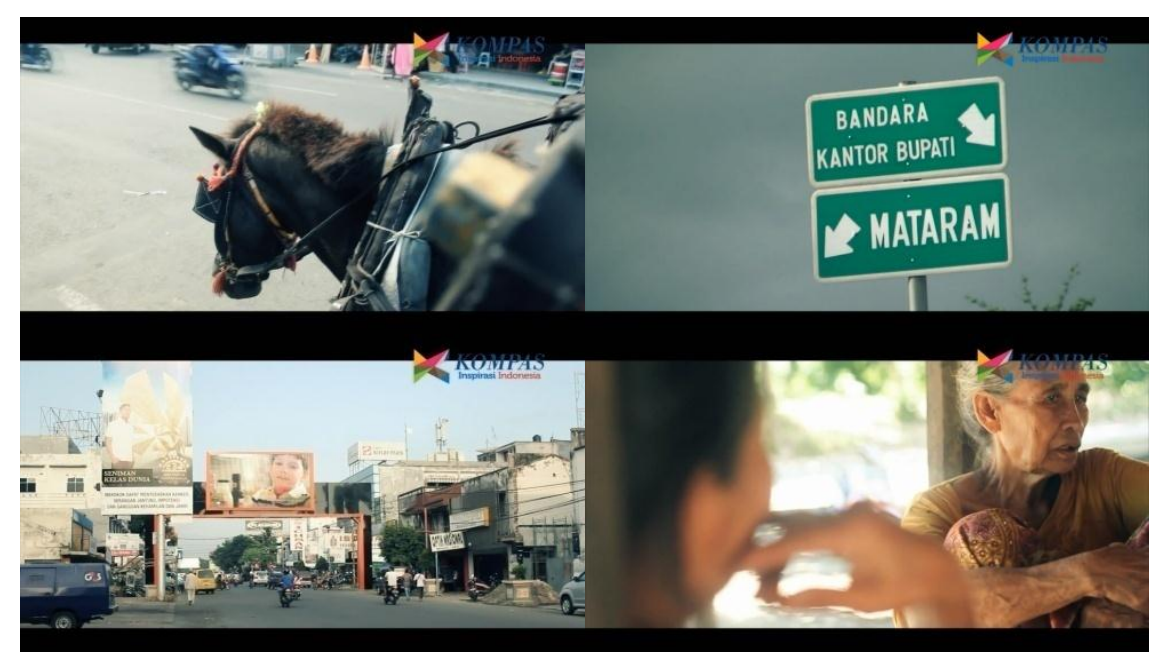

Gambar. 5 Kota Mataram dan penduduk Suku Sasak (Sumber: Dokumentasi penulis)

\section{c. Suku Sasak Desa Sade}

Desa Sade adalah desa yang terletak di bagian tengah dari pulau Lombok. Desa ini dihuni oleh Suku Sasak yang masih trdisional. Kesenian utama yang menjadi daya tarik para wisatawan adalah kain tenunnya. Desa ini merupakan objek utama para wisatawan yang berkunjung ke pulau Lombok.

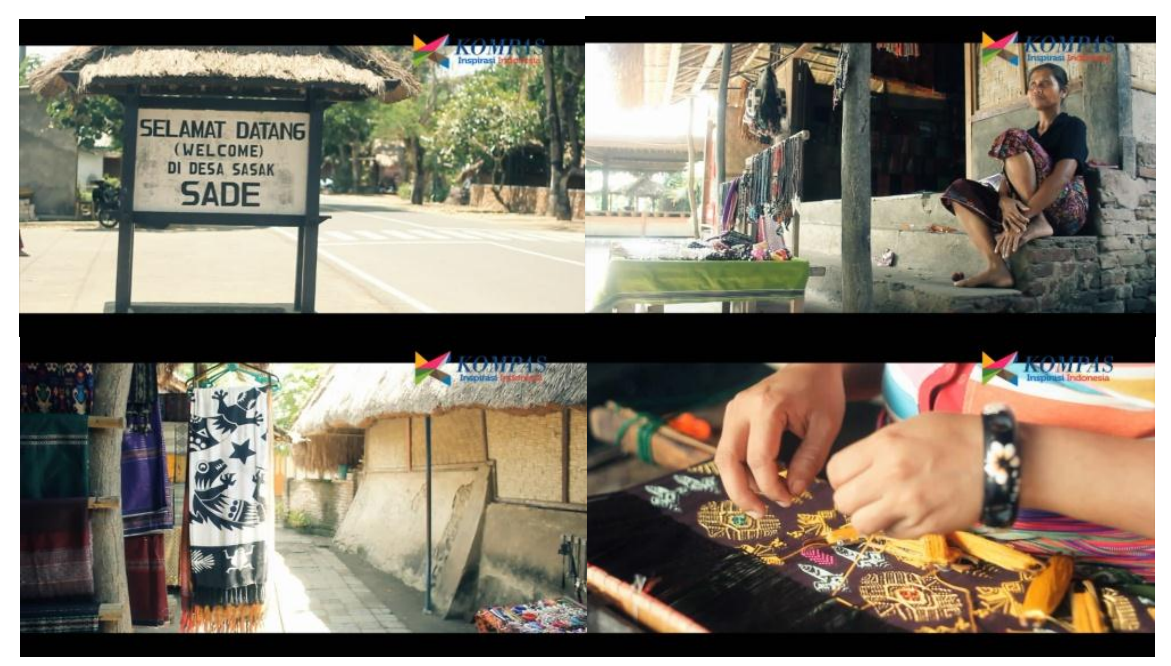

Gambar. 6 Desa Sade

(Sumber: Dokumentasi penulis)

\section{d. Suku Sasak Desa Bayan}

Suku Sasak Desa Bayan terletak di bagian utara pulau Lombok di dekat kaki gunung Rinjani. Memperlihatkan suasana rumah adat Sasak desa Bayan serta keadaan penduduknya yang masih tradisional. 


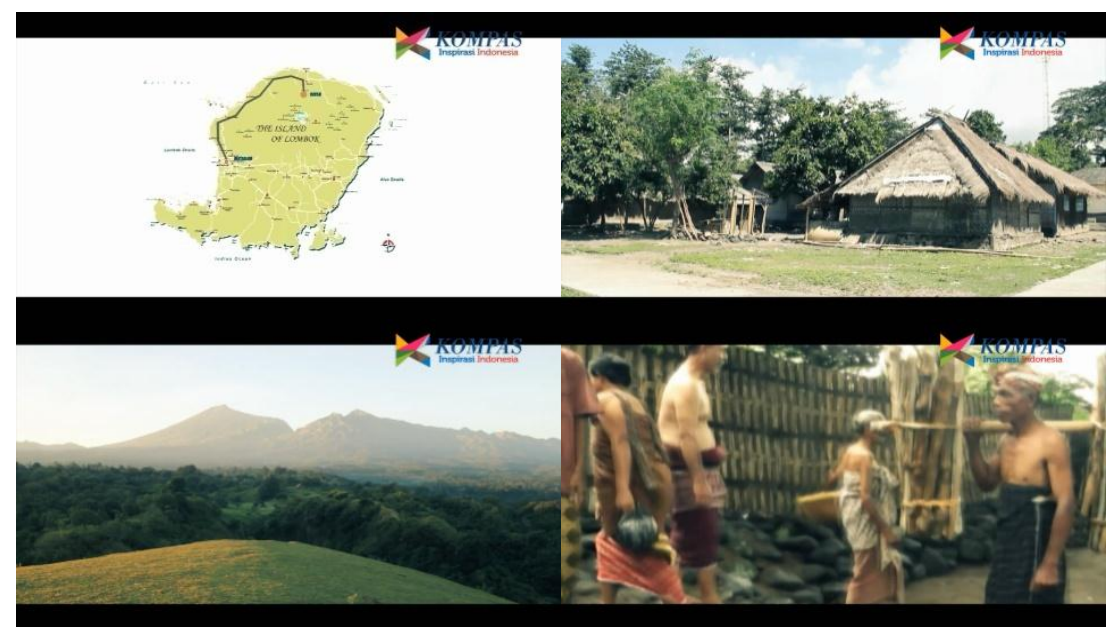

Gambar.7 Desa Bayan Lombok Utara (Sumber: Dokumentasi penulis)

\section{e. Masjid Bayan}

Masjid Bayan adalah peninggalan sakral umat Islam Suku Sasak di Desa Bayan. Biasanya hanya digunakan pada upacara adat tertentu dan hanya pemuka agama yang boleh masuk ke dalamnya.

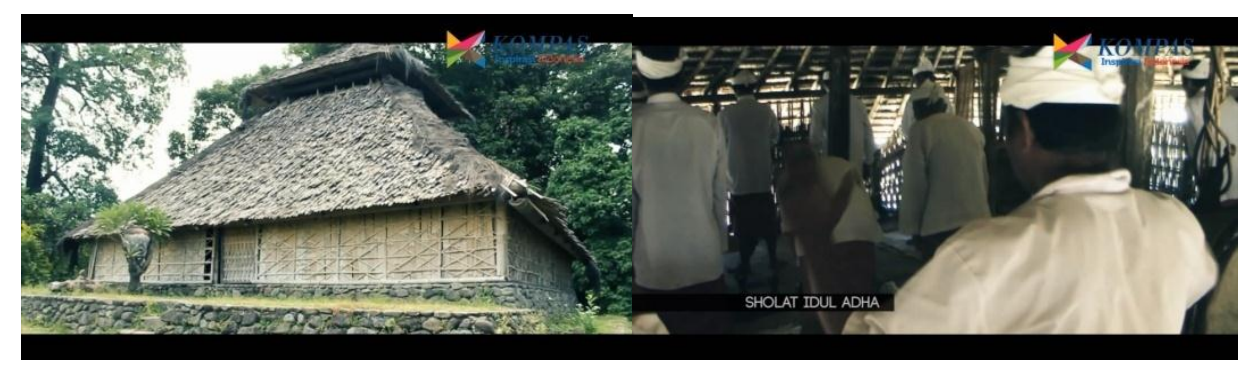

Gambar. 8 Masjid Bayan

(Sumber: Dokumentasi penulis)

\section{f. Islam Wetu Telu}

Islam Wetu Telu merupakan salah satu mitos yang selama ini banyak orang yang salah kaprah dengan pengertiannya. Dalam hal ini yang dimaksud adalah keselarasan hidup antara manusia, alam, dan Sang Pencipta.

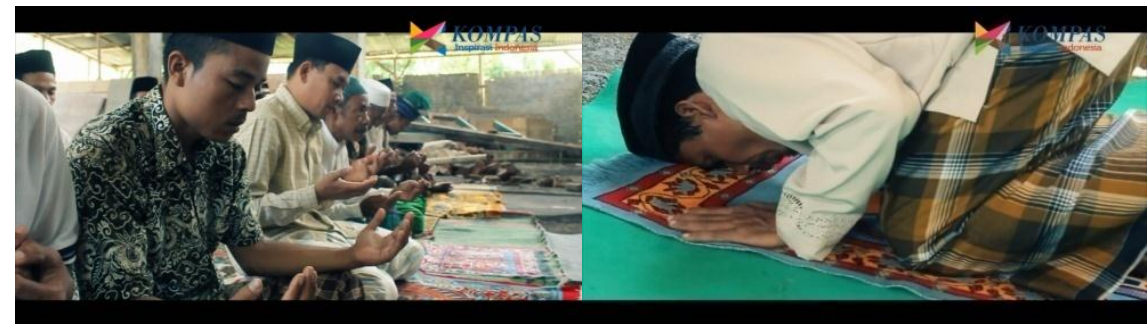

Gambar.9 Islam di masyarakat Sasak Bayan 


\section{g. Mata Pencaharian Suku Sasak Bayan}

Masyarakat desa Bayan memiliki mayoritas mata pencaharian di bidang pertanian, perkebunan, dan peternakan. Hal itu dikarenakan mereka percaya bahwa alam menyediakan segala sesuatu bagi kehidupan mereka.

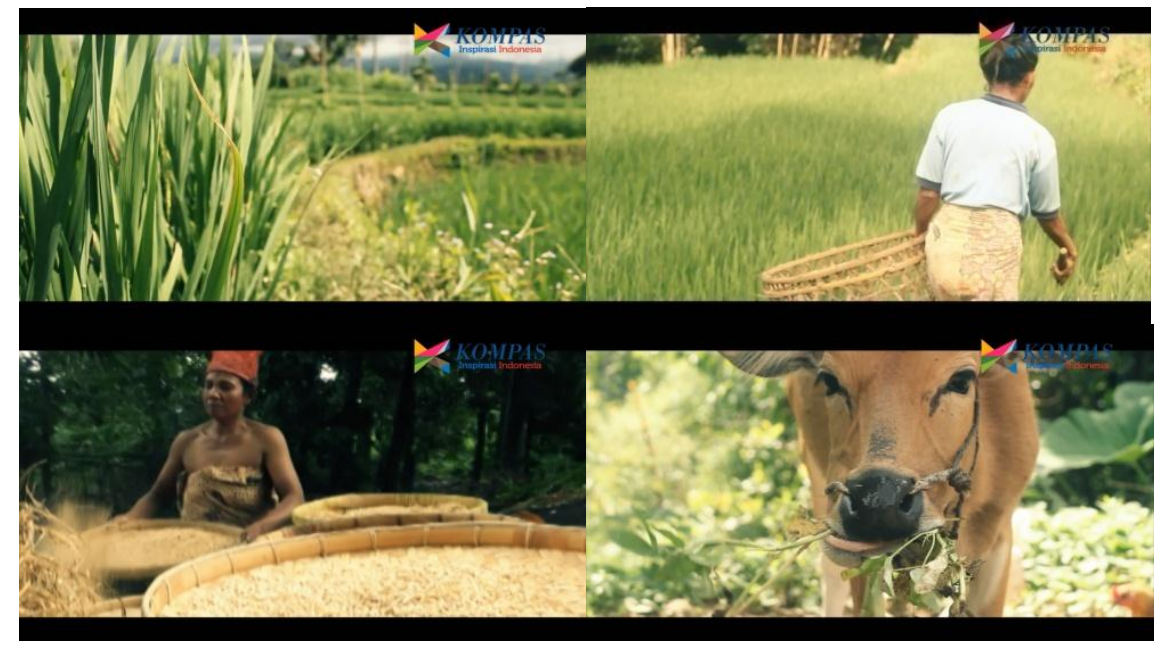

Gambar.10 Suasana alam Desa Bayan

(Sumber: Dokumentasi penulis)

\section{h. Adat Tradisional Suku Sasak}

Berisi dokumentasi tentang kegiatan adat asli dari Masyarakat Suku Sasak Desa Bayan. Peristiwa adat ini jarang terjadi di masyarakat dan menarik untuk disimak. Pakaian adat ran ritual sakral menghiasi rangkaian upacara adat.

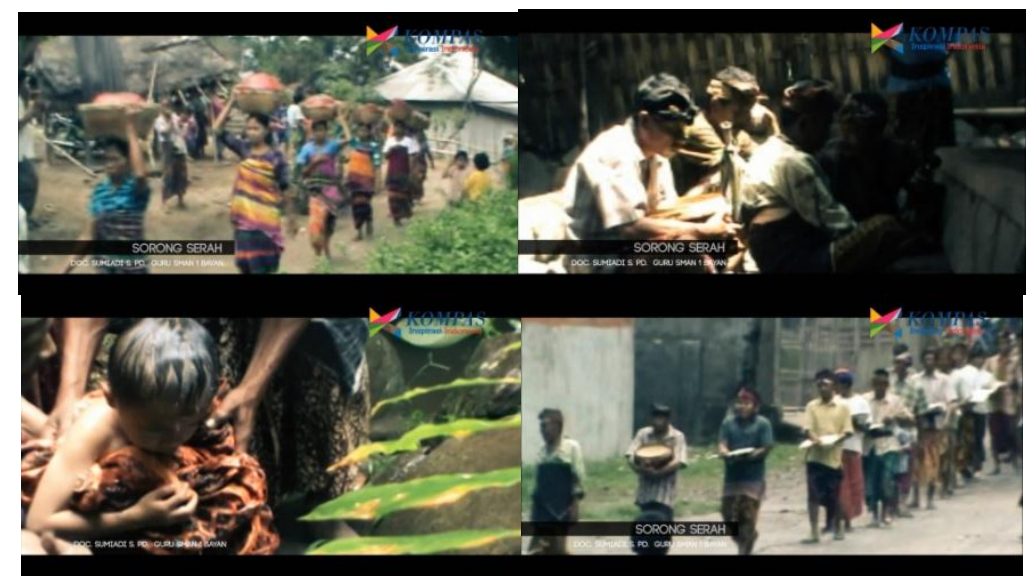

Gambar. 11 Acara Adat Sasak Bayan

(Sumber: Dokumentasi penulis) 


\section{i. Dokumentasi Pariwisata Suku Sasak}

Berisi mengenai beberapa kegiantan budaya dari Suku Sasak yang berkaitan dengan promosi wisata pulau Lombok. Kegiatan ini tidak hanya diadakan di pulau Lombok saja, tetapi juga sampai ke luar pulau seperti di Jakarta dan Yogyakarta.

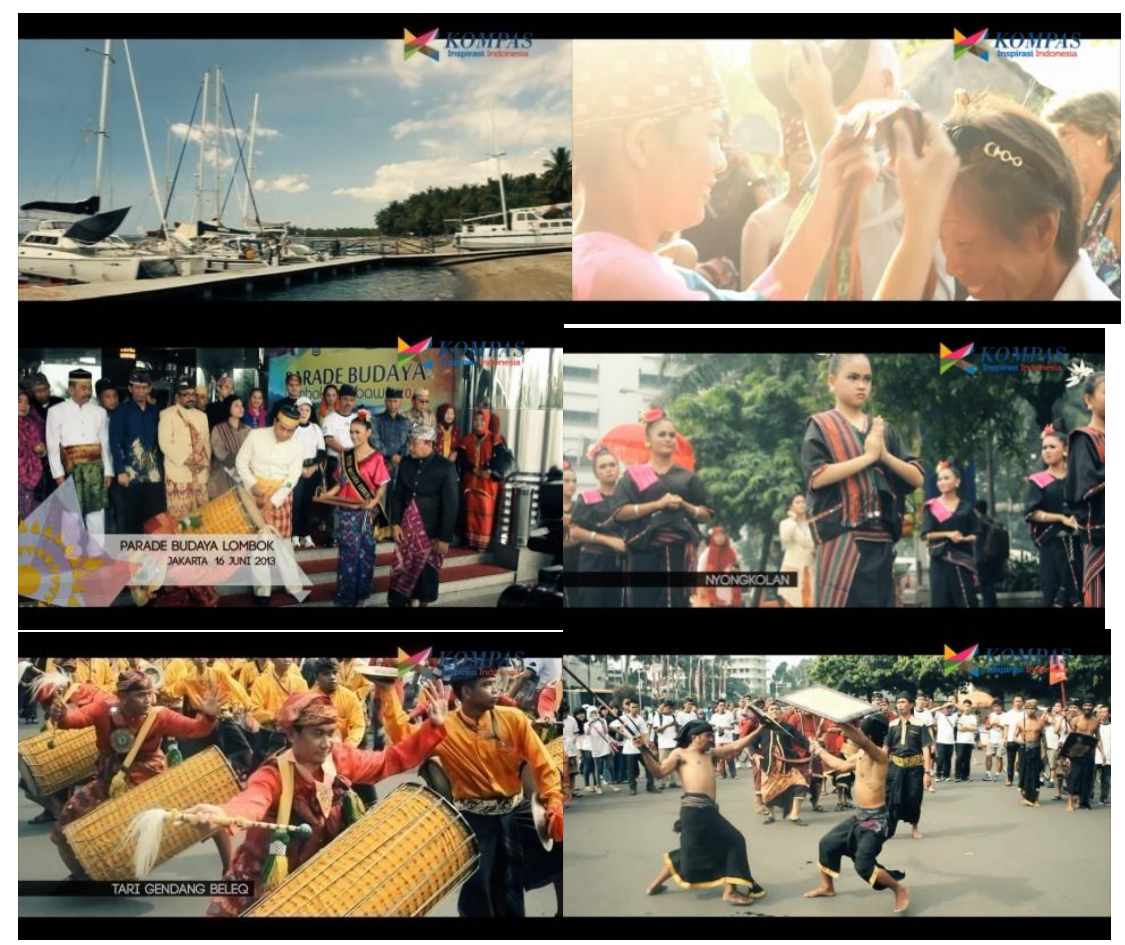

Gambar. 12 Kegiatan pariwisata suku Sasak

(Sumber: Dokumentasi penulis)

\section{Gaya Ilustrasi}

Gaya ilustrasi pada opening dan grafis menggunakan style Kompas TV sebagai acuan yang dikolaborasikan dengan etnik. Gaya desain pada Kompas TV cenderung formal dan sedikit eksklusif, hal ini akan dikombinasikan dengan ornamen yang berbau etnik dari kebudayaan suku sasak.

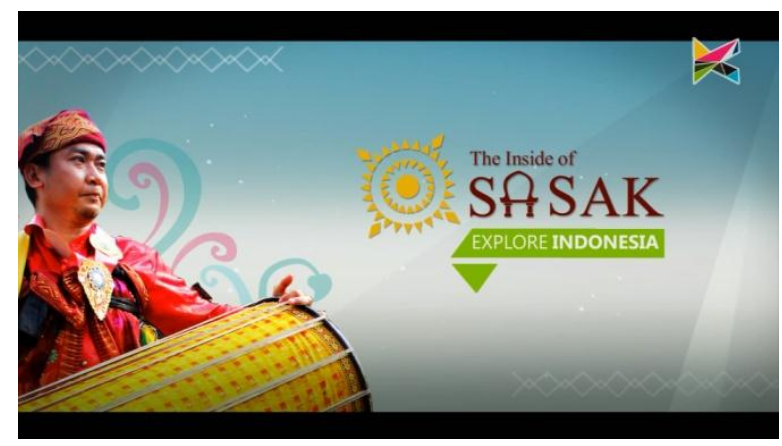

Gambar. 13 Bumper "The Inside of Suku Sasak" (Sumber: Dokumentasi penulis) 


\section{Jenis Tipografi}

Tipografi juga berperan pada penjelasan narasi atau narasumber yang ada. Sehubungan dengan gaya dari Kompas TV dan National Geography yang formal selaku referensi, maka font yang digunakan pun menggunakan font yang resmi. Di sini font yang akan digunakan adalah font yang cenderung lurus dan tebal untuk memberi kesan formal dan tegas.

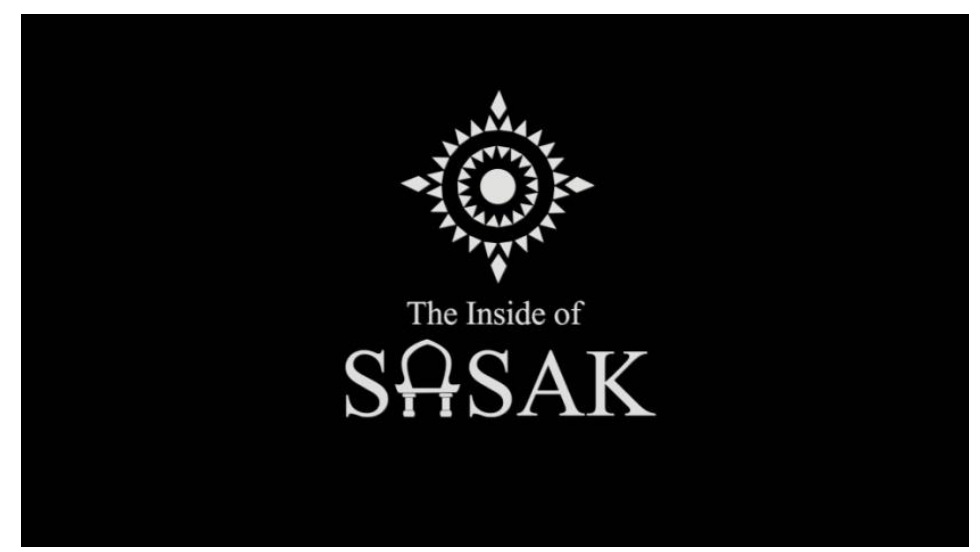

Gambar. 14 Font yang dipakai

\section{Deskripsi Suara}

\section{Musik Latar}

Pada opening menggunakan backsound dari musik asli suku Sasak yang berasal dari alat musiknya. Untuk bagian kegiatan sehari-hari menggunakan backsound dengan tempo yang rendah, sedangkan pada bagian kegiatan adat menggunakan backsound dengan tempo yang lebih cepat. Untuk bagian Intrik cerita menggunakan musik yang pelan dan sedikit menakutkan. Bagian yang paling seru adalah ketika melakukan Perang Paresean, digunakan backsound dengan tema peperangan untuk memperkaya suasana. Sedangkan bagian ending diberikan backsound musik yang membawa semangat dan menyentuh.

\section{Sound Effect}

Sound Effect yang dipakai pada beberapa scene adalah suara genderang perang ketika bertarung, suara alam dan kicauan burung ketika di pagi hari, dan juga alunan musik rohani ketika mengaji. Musik tradisional juga disisipkan sebagai ciri khas dari suku Sasak.

\section{Dubbing Narasi}

Dubbing konten dari cerita dilakukan oleh orang lain yang memiliki suara yang bagus dan berwibawa, lebih diutamakan laki-laki. Untuk menimbulkan kesan yang lebih berwibawa dan lebih terkesan gentle karena yang diangkat di sini adalah karakter laki-laki. 


\section{Voice Over ( Narasumber )}

Untuk memperoleh keakuratan mengenai suatu keterangan maka diperlukan suatu wawancara oleh sumber yang berkopeten dan dipercaya. Wawancara ini perlu direkam dan ditampilkan untuk memperkuat narasi yang ada.

\section{Konsep Perancangan Media Pendukung}

Dari consumer inside dan journey bisa diperoleh data yang digunakan sebagai acuan untuk memilih media pendukung. Hal-hal apa saja yang dibutuhkan dan yang menjadi point of contact dari target segmen juga menentukan pemilihan media yang tepat nantinya. Media pendukung juga berfungsi sebagai second line dari promosi untuk mengenalkan produk dokumenter itu ke masyarakat luas. Contohnya adalah:

a. Poster program tayang di salah satu stasiun TV Nasional. Poster memiliki kegunaan sebagai pemberi informasi kepada masyarakat mengenai hari tayang program Explore Indonesia.

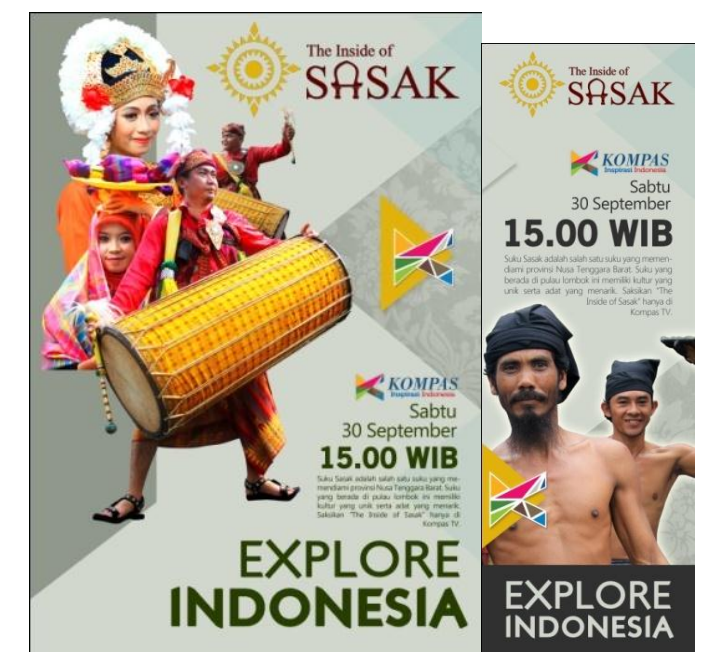

Gambar. 15 Poster dan flyer

b. Iklan promo TV merupakan media yang paling ampuh untuk mempromosikan suatu program acara kepada pemerhati Kompas TV.

c. Video on Youtube, dengan adanya bantuan dari media youtube, video bisa diunggah ke Youtube sehingga bisa diakses kapan saja. Iklan promo dari Explore Indonesia edisi Suku Sasak juga bisa diunggah sehingga bisa di link ke media-media sosial untuk promosi.

d. DVD Program acara ini sangat disayangkan jika tidak didistribusikan ke masyarakat luar. Dengan adanya media ini merupakan salah satu tambahan sebagai bahan koleksi 
buat orang yang menyukai kebudayaan Indonesia, bahkan wisatawan asing sehingga secara tidak langsung dapat menjadi media promosi untuk visit Indonesia.

e. Foto dokumenter, sebagai media pendukung view thumbnail dari program acara yang dipromosikan pada website Kompas.TV. Foto dokumenter bersifat lebih dramatis sehingga mampu membuat penasaran orang yang akan melihatnya.

\section{KESIMPULAN}

Untuk membuat suatu program acara dokumenter diperlukan suatu persiapan yang matang mulai dari riset yang dilakukan hingga pengerjaan video mulai dari pra produksi, produksi, dan final editing. Video dokumenter ini meruapkan suatu alternatif media untuk mempelajari kebudaayaan Indonesia yang dalam hal ini adalah suku Sasak.

\section{DAFTAR PUSTAKA}

Badan Pusat Statistik Cabang Mataram. (2001). Mataram: Badan Pusat Statistik

Baksin, Askurifai. (2009). Videografi (Aplikasinya untuk Berita, Film, Video Klip, dan Perkawinan). Padjajaran: Widya Padjajaran.

Budiwanti, Erni. (2000). Islam Sasak, Islam Wetu Telu versus Wetu Limo. Yogyakarta: LkiS

Danesi, Marcell. (2012). Pesan, Tanda, dan Makna. Cetakan: III. Jakarta: Jalasutra.

Departemen Pendidikan dan Kebudayaan. (1985). Dampak Modernisasi Terhadap Hubungan Kekerabatan di Nusa Tenggara Barat.

Departemen Pendidikan dan Kebudayaan. (1988). Peralatan, Hiburan, dan Kesenian Tradisional Daerah Nusa Tenggara Barat.

Effendi, Heru. (2002). Mari Membuat Film: Panduan menjadi Produser. Jakarta: Yayasan Konfiden. Hayward, Susan. (1996). Key Concept in Cinema Studies. Taylor \& Francis Group.

Kamus Besar Bahasa Indonesia. (1990). Film. Jakarta: Balai Pustaka.

Marrison, Geofrey. (1999). Sasak and Javaness Literture. Leiden: KITLV Press.

Melatoa, Junus. (1995). Ensiklopedia Suku Bangsa Sasak di Indonesia. Jakarta: Eka Putera.

M Suyanto. (2008). Strategi Perancangan Iklan Televisi Perusahaan Top Dunia. Yogyakarta: Andi Offset.

Nugroho, Fajar. (2007). Cara Pinter Bikin Film Dokumenter. Cetakan: I. Yogyakarta: Galang Press.

Rustan, Surianto. (2011). Hurufontipografi. Jakarta: Gramedia Pustaka Utama.

Wibowo, Fred. (2007). Teknik Produksi Program Televisi. Yogyakarta: Pinus. 
(1997). Dasar-Dasar Produksi Program televisi. Jakarta: Grasindo. 